\title{
Geometry analysis and optimal design of Geneva mechanisms with curved slots
}

\author{
J-J Lee* and K-F Huang \\ Department of Mechanical Engineering, National Taiwan University, Taipei, Taiwan
}

\begin{abstract}
A systematic procedure is proposed for the design of Geneva mechanisms with curved slots. Based on the theory of conjugate surfaces, mathematical expressions for the slot profile, pressure angle and cutter's location for manufacturing are presented. In addition, to evaluate the combined kinematics and structural performance of the mechanism, the maximum contact stress and degree of wear are established as the performance index. Effects of variations in various design parameters on the values of the performance indices are investigated. Using the indices as the objective function, the optimum design that takes into account the initial crank angle, offset and roller radius is performed.
\end{abstract}

Keywords: Geneva mechanism with curved slots, surface geometry, conjugate surfaces, optimum design

\section{NOTATION}

$E_{i}$

$f_{\mathrm{c}}$

$h$

$I_{\mathrm{w}}$

$\ell$

${ }^{\mathrm{f}} \mathbf{n}_{\mathrm{p}}$

$N$

${ }^{r}{ }^{\mathrm{f}}$

${ }^{\mathrm{f}} \boldsymbol{r}_{\mathrm{p}}$

${ }^{j} \mathbf{T}_{i}$

${ }^{\mathrm{f}} \boldsymbol{v}_{\mathrm{p}}$

$\alpha$

$\theta_{\mathrm{d}}$

$\theta_{\mathrm{d} 0}$

$\theta_{\text {off }}$

$\theta_{\mathrm{w}}$

$v_{i}$
Young's modulus of elasticity for material $i$

compressive contact force

wheel thickness

rotary inertia of the wheel

base radius of wheel

unit surface normal at point $\mathrm{P}$ with

respect to the frame

number of slots

radius of the roller

position vector of point $\mathrm{P}$ with respect to

the frame

transformation matrix from system $i$ to

system $j$

velocity vector of point $\mathrm{P}$ with respect to

the frame

surface parameter of cylindrical roller

angular position of the crank

initial angular position of the crank

offset angle

angular position of the wheel

Poisson's ratio of material $i$

The MS was received on 20 A ugust 2003 and was accepted after revision for publication on 15 January 2004.

* Corresponding author: Department of Mechanical Engineering, National Taiwan University, 1 Roosevelt Road, Section 4, Taipei,

Taiwan 106.

$\begin{array}{ll}\rho_{\mathrm{fmin}} & \begin{array}{l}\text { minimum radius of curvature of the cam } \\ \text { pitch curve } \\ \text { minimum radius of curvature of the } \\ \rho_{\text {min }}\end{array} \\ \sigma_{\mathrm{m}} & \begin{array}{l}\text { mancave curve } \\ \text { wheel slot and roller surfaces }\end{array} \\ \psi & \begin{array}{l}\text { pressure angle } \\ \omega_{\mathrm{d}}\end{array} \\ \omega_{\mathrm{w}} & \begin{array}{l}\text { angular velocity of the driving crank } \\ \text { angular velocity of the wheel }\end{array}\end{array}$

\section{INTRODUCTION}

For decades, Geneva mechanisms have been commonly used in the automation area where intermittent motion is demanded. The design and manufacture of a conventional Geneva mechanism is generally simple since its structure contains a driving link and a wheel with straight slots. However, the disadvantage of using the conventional Geneva mechanism is the impact loading at the initial and final stages when the crank pin engages and disengages with the wheel slot. This phenomenon degrades the mechanism to low speed applications or places where noise and vibration are of no major concern. In order to eliminate the impact loading at initial and final stages of operation, several methods have been proposed. The methods of approach can be noted as follows. In the first classification, as proposed in references [1] to [5], compound mechanisms were used to eliminate the non-zero accelerations at the 
initial and final stages. In this method, two or more mechanisms are connected in series such that the acceleration of the wheel at the final stage increases gradually and ends smoothly at the end of the motion cycle. This inevitably increases extra components for the system. In the second classification, as mentioned by Sadek et al. [6] and Cheng and Lin [7], a certain damping element was installed in the mechanism to reduce the shock. Similarly, specially designed extra components are required in the method. The third approach as performed by Fenton et al. [8] and Lee [9] was to change the geometry of the wheel slot. The displacement curve for output motion was discussed. However, basic equations for the surface geometry of the slots were not available in the approach.

Therefore, it is the objective of this paper to synthesize the surface geometry of Geneva mechanisms with curved slots. In what follows, basic equations of surface geometry will first be derived via the theory of conjugate surfaces. Then, the pressure angle, manufacturing condition and structural performance indexes of a Geneva mechanism with curved slots are also derived systematically. Furthermore, effects of variations in various design parameters on the performance of the mechanism are investigated. Two indices, maximum surface stress and degree of wear, for the evaluation of the mechanism are developed. Finally, numerical examples of the optimal design in accordance with the two indices are presented.

\section{SURFACE GEOMETRY}

In this section, the mathematical expressions for the surface geometry of the Geneva mechanism with curved slots are derived via the theory of conjugate surfaces. In this work, the cylindrical roller is adopted. Since the slot of the wheel is generated by the motion of the crank, the contact points of the two conjugate surfaces are defined according to the equation of meshing and the specified input-output relation. These contact points determine the generated surfaces on the wheel. They can be obtained by transforming the coordinates from the coordinate system on the roller to the coordinate system on the wheel. Figure 1 shows the Geneva mechanism with the roller engaging with the curved slot. The wheel contains $N$ identical and equally spaced curved slots and $\mathrm{O}_{1}$ and $\mathrm{O}_{2}$ are respectively the centres of the wheel and the driving crank. A cylindrical roller with radius $r$ is located at the tip $\mathrm{C}$ of the crank. At the beginning, the roller enters the slot at point $\mathrm{M}$. The distance between the wheel centre and point $\mathrm{M}, \mathrm{O}_{1} \mathrm{M}$, is adopted as the base radius of the wheel. After time $t$, the crank drives the wheel to a position where the angle between the line $\mathrm{O}_{1} \mathrm{M}$ and centre-line $\mathrm{O}_{1} \mathrm{O}_{2}$ is $\theta_{\mathrm{w}}$. The corresponding angular position of the crank, $\mathrm{O}_{2} \mathrm{C}$, relative to centre-

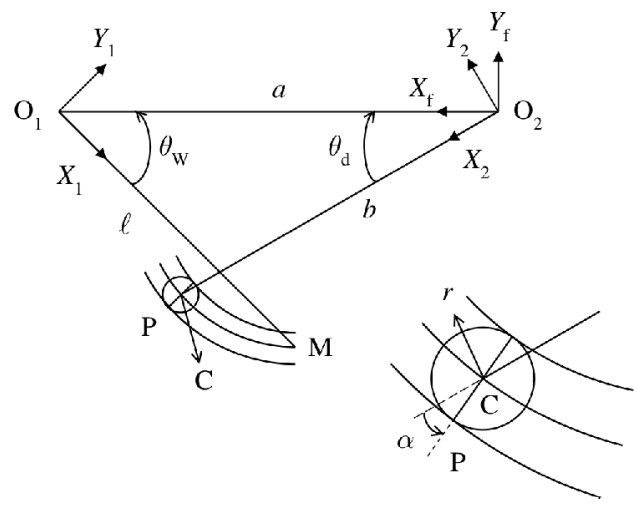

Fig. 1 Definition of the coordinate systems of the mechanism

line $\mathrm{O}_{1} \mathrm{O}_{2}$ is denoted by $\theta_{\mathrm{d}}$. Note that the initial values of $\theta_{\mathrm{w}}$, denoted as $\theta_{\mathrm{w} 0}$, and $\theta_{\mathrm{d}}$, denoted as $\theta_{\mathrm{d} 0}$, and the links geometry can be related by the sine law as

$$
\begin{aligned}
& \frac{\ell}{\sin \left(\theta_{\mathrm{d} 0}\right)}=\frac{b}{\sin \left(\theta_{\mathrm{w} 0}\right)}=\frac{a}{\sin \left(\pi-\theta_{\mathrm{d} 0}-\theta_{\mathrm{w} 0}\right)} \\
& \theta_{\mathrm{w} 0}=\frac{\pi}{N}
\end{aligned}
$$

where $\ell=\mathrm{O}_{1} \mathrm{M}, b=\mathrm{O}_{2} \mathrm{C}, a=\mathrm{O}_{1} \mathrm{O}_{2}$ and $N$ is the number of slots.

Let the coordinate systems on the mechanism be defined as: $X_{1}-Y_{1}-Z_{1}$ attached to the wheel with the origin located at the rotating centre of the wheel and the $X_{1}$ axis pointing to the point $\mathrm{M} ; X_{2}-Y_{2}-Z_{2}$ attached to the crank with the origin located at the rotating centre of the crank and the $X_{2}$ axis pointing to the centre of the roller; and $X_{\mathrm{f}}-Y_{\mathrm{f}}-Z_{\mathrm{f}}$ attached to the frame with the origin coincident with $\mathrm{O}_{2}$. Then, transformation matrices of the coordinate systems can be obtained as

$$
{ }^{\mathrm{f}} \mathbf{T}_{2}=\left[\begin{array}{cccc}
\mathrm{C} \theta_{\mathrm{d}} & \mathrm{S} \theta_{\mathrm{d}} & 0 & 0 \\
-\mathrm{S} \theta_{\mathrm{d}} & \mathrm{C} \theta_{\mathrm{d}} & 0 & 0 \\
0 & 0 & 1 & 0 \\
0 & 0 & 0 & 1
\end{array}\right]
$$

and

$$
{ }^{1} \mathbf{T}_{\mathrm{f}}=\left[\begin{array}{ccrc}
-\mathrm{C} \theta_{\mathrm{w}} & -\mathrm{S} \theta_{\mathrm{w}} & 0 & a \mathrm{C} \theta_{\mathrm{w}} \\
-\mathrm{S} \theta_{\mathrm{w}} & \mathrm{C} \theta_{\mathrm{w}} & 0 & a \mathrm{~S} \theta_{\mathrm{w}} \\
0 & 0 & -1 & 0 \\
0 & 0 & 0 & 1
\end{array}\right]
$$

where $\mathrm{C}=\cos$ and $\mathrm{S}=\sin$ and ${ }^{j} \mathbf{T}_{i}$ denotes the transformation matrix from system $i$ to system $j$.

Consider a conjugate contact point $\mathrm{P}$. The position vector of $\mathrm{P}$ on the roller with respect to the coordinate system $X_{\mathrm{f}}-Y_{\mathrm{f}}-Z_{\mathrm{f}}$ can be written as

$$
{ }^{\mathrm{f}} \boldsymbol{r}_{\mathrm{p} 2}=\left[b \mathrm{C} \theta_{\mathrm{d}}+r \mathrm{C}\left(\theta_{\mathrm{d}}+\alpha\right),-b \mathrm{~S} \theta_{\mathrm{d}}-r \mathrm{~S}\left(\theta_{\mathrm{d}}+\alpha\right), 0\right]^{\mathrm{T}}
$$

where the superscript ' $\mathrm{f}$ ' represents the coordinate 
system to which the vector is referred and $\alpha$ is the surface parameter of the cylindrical roller. The unit surface normal of the cylindrical roller at the contact point can be expressed as

$$
{ }^{\mathrm{f}} \boldsymbol{n}_{\mathrm{p} 2}=\left[\mathbf{C}\left(\theta_{\mathrm{d}}+\alpha\right),-\mathrm{S}\left(\theta_{\mathrm{d}}+\alpha\right), 0\right]^{\mathrm{T}}
$$

When the crank rotates at a constant angular velocity $\omega_{\mathrm{d}}$ about $Z_{\mathrm{f}}$ axis, the wheel rotates at an angular speed $\omega_{\mathrm{w}}$ about the $Z_{1}$ axis. Then the velocity of conjugate point $\mathrm{P}$ on the roller with respect to the frame, ${ }^{\mathrm{f}} \boldsymbol{v}_{\mathrm{p} 2}$, is given by

$$
\begin{aligned}
{ }^{\mathrm{f}} \boldsymbol{v}_{\mathrm{p} 2} & =\omega_{\mathrm{d}} \times{ }^{\mathrm{f}} \boldsymbol{r}_{\mathrm{p} 2}=\left(\boldsymbol{\omega}_{\mathrm{d}} \boldsymbol{k}_{\mathrm{f}}\right) \times{ }^{\mathrm{f}} \boldsymbol{r}_{\mathrm{p} 2} \\
& =\omega_{\mathrm{d}}\left[b \mathrm{~S} \theta_{\mathrm{d}}+r \mathrm{~S}\left(\theta_{\mathrm{d}}+\alpha\right), b \mathrm{C} \theta_{\mathrm{d}}+r \mathrm{C}\left(\theta_{\mathrm{d}}+\alpha\right), 0\right]^{\mathrm{T}}
\end{aligned}
$$

where $\omega_{\mathrm{d}}$ is the angular speed of the driving crank. On the other hand, the velocity of $\mathrm{P}$ on the wheel with respect to the frame, ${ }^{\mathrm{f}} \boldsymbol{v}_{\mathrm{p} 1}$, is given by

$$
\begin{gathered}
{ }^{\mathrm{f}} \boldsymbol{v}_{\mathrm{p} 1}=\boldsymbol{\omega}_{\mathrm{w}} \times \mathbf{O}_{1} \mathbf{P}=\left[-\left(\frac{\mathrm{d} \theta_{\mathrm{w}}}{\mathrm{d} t}\right) \boldsymbol{k}_{\mathrm{f}}\right] \times\left(-a \boldsymbol{i}_{\mathrm{f}}+{ }^{\mathrm{f}} \boldsymbol{r}_{\mathrm{p} 2}\right) \\
=-\omega_{\mathrm{d}}\left[\theta_{\mathrm{w}}^{\prime}\left(b \mathrm{~S} \theta_{\mathrm{d}}+r \mathrm{~S}\left(\theta_{\mathrm{d}}+\alpha\right)\right),\right. \\
\left.\theta_{\mathrm{w}}^{\prime}\left(b \mathrm{C} \theta_{\mathrm{d}}+r \mathrm{C}\left(\theta_{\mathrm{d}}+\alpha\right)-a\right), 0\right]^{\mathrm{T}}
\end{gathered}
$$

where $\theta_{\mathrm{w}}^{\prime}=\mathrm{d} \theta_{\mathrm{w}} / \mathrm{d} \theta_{\mathrm{d}}$.

Since the surface normal vector, ${ }^{\mathrm{f}} \boldsymbol{n}_{\mathrm{p} 2}$, and the relative velocity between the roller surface and the wheel surface, ${ }^{\mathrm{f}} \boldsymbol{v}_{\mathrm{p} 2}-{ }^{\mathrm{f}} \boldsymbol{v}_{\mathrm{p} 1}$, must be orthogonal at the contact point, the condition of contact (or the condition of meshing) $[\mathbf{1 0}, \mathbf{1 1}]$ can thus be written as

$$
{ }^{\mathrm{f}} \boldsymbol{n}_{\mathrm{p} 2} \cdot\left({ }^{\mathrm{f}} \boldsymbol{v}_{\mathrm{p} 2}-{ }^{\mathrm{f}} \boldsymbol{v}_{\mathrm{p} 1}\right)=0
$$

Substituting equations (3), (4) and (5) into equation (6) and simplifying yields

$$
\alpha=\tan ^{-1}\left[\frac{a \theta_{\mathrm{w}}^{\prime} \mathrm{S} \theta_{\mathrm{d}}}{\left(1+\theta_{\mathrm{w}}^{\prime}\right) b-a \theta_{\mathrm{w}}^{\prime} \mathrm{C} \theta_{\mathrm{d}}}\right]
$$

Note that Equation (7) yields two values, corresponding to two different points, while the roller is contacting with the wheel. The corresponding conjugate profile of the wheel, ${ }^{\mathrm{f}} \boldsymbol{r}_{\mathrm{p} 1}$, can thus be obtained by transforming to the wheel coordinate system, as

$$
\left[\begin{array}{c}
{ }^{1} \boldsymbol{r}_{\mathrm{p}} \\
1
\end{array}\right]={ }^{1} \mathbf{T}_{\mathrm{f}}\left[\begin{array}{c}
{ }^{\mathrm{f}} \boldsymbol{r}_{\mathrm{p}} \\
1
\end{array}\right]
$$

or

$$
\begin{aligned}
{ }^{1} \boldsymbol{r}_{\mathrm{p} 2}= & {\left[a \mathrm{C} \theta_{\mathrm{w}}-b \mathrm{C}\left(\theta_{\mathrm{w}}+\theta_{\mathrm{d}}\right)-r \mathrm{C}\left(\theta_{\mathrm{w}}+\theta_{\mathrm{d}}+\alpha\right),\right.} \\
& \left.a \mathrm{~S} \theta_{\mathrm{w}}-b \mathrm{~S}\left(\theta_{\mathrm{w}}+\theta_{\mathrm{d}}\right)-r \mathrm{~S}\left(\theta_{\mathrm{w}}+\theta_{\mathrm{d}}+\alpha\right), 0\right]^{\mathrm{T}}
\end{aligned}
$$

Therefore, once the relation between the crank angle $\theta_{\mathrm{d}}$ and the wheel angle $\theta_{\mathrm{w}}$ is prescribed, conjugate points of the complete profile of the wheel that correspond to meshing the roller can be obtained, according to equations (7) and (8). It should be noted that the displacement function that relates the crank and wheel angles should be continuous through at least the second derivatives across the operating interval in order to avoid any discontinuities in the acceleration function.

\subsection{Pressure angle}

Unlike the traditional Geneva mechanism with a straight slot where the force exerted on the slot sidewall always points along the motion of the wheel, the pressure angle of the Geneva mechanism with curved slots varies during operation. The pressure angle is regarded as an important index for motion and force transmission. The larger the pressure angle, the higher the radial force of the wheel may be and the more inefficient the power transmission from the input to the output may become. Furthermore, the slot may be exposed to larger wear when the pressure angle is large, as will be discussed in a later section. The pressure angle can be defined as the angle subtended between the direction of the applied force on the driven member and the direction of the velocity at the contact point on the driven member. Thus, the pressure angle at the contact point on the slot can be defined as

$$
\cos \psi={ }^{\mathrm{f}} \boldsymbol{n}_{\mathrm{p} 2} \cdot\left(\frac{{ }^{\mathrm{f}} \boldsymbol{v}_{\mathrm{p} 1}}{\left|{ }^{\mathrm{f}} \boldsymbol{v}_{\mathrm{p}}\right|}\right)
$$

Substituting equations (3) and (5) into the above equation yields

$$
\cos \psi=\frac{b \mathrm{~S} \alpha-a \mathrm{~S}\left(\theta_{\mathrm{d}}+\alpha\right)}{\left[a^{2}+b^{2}+r^{2}-2 a b \mathrm{C} \theta_{\mathrm{d}}-2 a r \mathrm{C}\left(\theta_{\mathrm{d}}+\alpha\right)+2 b r \mathrm{C} \alpha\right]^{1 / 2}}
$$

\subsection{Condition of undercutting}

During the machining process, the cutter size is generally chosen to be the same as that of the roller. Thus, coordinates of the cutter's location can be obtained by setting the roller radius $r=0$ in equation (8). In such a condition, undercutting should be avoided or the motion of the driven link will not be as prescribed. To avoid undercutting, the following conditions must be obeyed [12]:

1. When the roller is mating with the concave curve,

$$
\left|\rho_{\min }\right|>r
$$

2. When the roller is mating with the convex curve,

$$
\left|\rho_{\text {fmin }}\right|>r
$$

where $\left|\rho_{\text {fmin }}\right|$ is the absolute value of the minimum 


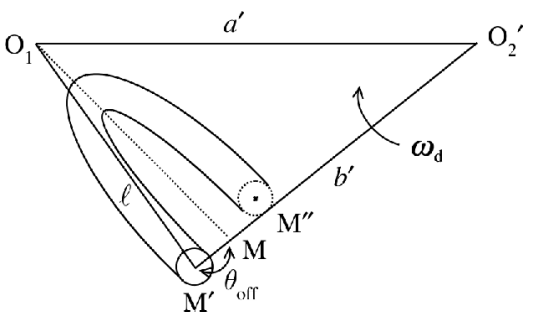

Fig. 2 Offset of the curved slot

radius of curvature of the concave curve and $\left|\rho_{\text {fmin }}\right|$ is the absolute value of the minimum radius of curvature of the cam pitch curve. Details of the derivation for the radius of curvature of the slot profile are given in the Appendix.

\subsection{Offset}

The geometry of the offset curved slot can be designed as shown in Fig. 2. As the roller is about to enter the slot at a new point $\mathrm{M}^{\prime}$, the angle between the line $\mathrm{O}_{1} \mathrm{M}^{\prime}$ and centre-line $\mathrm{O}_{1} \mathrm{O}_{2}^{\prime}$ becomes $\left(\theta_{\mathrm{w} 0}+\theta_{\text {off }}\right)$, where $\theta_{\text {off }}$ is the offset angle between the entry point $\mathrm{M}^{\prime}$ and the old entry point $\mathrm{M}$. As the crank finishes one cycle motion clockwise, the roller exits the slot at the exit point $\mathrm{M}^{\prime \prime}$. Comparing the geometry with the one without offset and remaining $\mathrm{O}_{1} \mathrm{M}^{\prime}$ and $\theta_{\mathrm{do}}$ as the invariant design parameters, the relationship of the new centre distance $\mathrm{O}_{1} \mathrm{O}_{2}^{\prime}$ and crank length $\mathrm{O}_{2} \mathrm{M}^{\prime}$ with the design parameters becomes

$$
\begin{aligned}
a^{\prime} & =\ell \frac{\sin \left(\pi-\theta_{\mathrm{d} 0}-\theta_{\mathrm{w} 0}-\theta_{\text {off }}\right)}{\sin \left(\theta_{\mathrm{d} 0}\right)} \\
b^{\prime} & =\ell \frac{\sin \left(\theta_{\mathrm{w} 0}+\theta_{\text {off }}\right)}{\sin \left(\theta_{\mathrm{d} 0}\right)}
\end{aligned}
$$

where $\mathrm{O}_{1} \mathrm{M}^{\prime}=\ell$. Thus, by replacing $a$ with $a^{\prime}$ and $b$ with $b^{\prime}$ in equations (7) and (8), the surface geometry of the offset curved slot can also be obtained.

\section{PERFORMANCE INDICES}

\subsection{Maximum contact stress}

In order to design a reliable mechanism, the maximum compressive contact stress should be less than an allowable compressive stress for both wheel and roller. This maximum contact stress can serve as a structural performance index for the mechanism. The maximum contact stress between the wheel slot and the roller surfaces is given by

$$
\sigma_{\mathrm{m}}=\sqrt{\frac{f_{\mathrm{c}}\left(1 / r_{1}+1 / r_{2}\right)}{\pi h\left[\left(1-v_{1}^{2}\right) / E_{1}+\left(1-v_{2}^{2}\right) / E_{2}\right]}}
$$

where $h$ is the wheel thickness, $r_{1}$ is the slot radius of curvature at the contact point, $r_{2}$ is the radius of the roller, $v_{1}$ and $v_{2}$ are Poisson's ratios for the wheel and roller, $E_{1}$ and $E_{2}$ are Young's modulii of elasticity for the wheel and roller and $f_{\mathrm{c}}$ is the normal contact force. The normal contact force is further given by

$$
\boldsymbol{f}_{\mathrm{c}}=\frac{I_{\mathrm{w}} \theta_{\mathrm{w}}^{\prime \prime}}{\ell^{\prime} \mathrm{C} \psi}
$$

where $I_{\mathrm{w}}$ is the rotary inertia of the wheel and $\ell^{\prime}$ is the distance between the wheel centre $\mathrm{O}_{1}$ and the contact point, as

$$
\ell^{\prime}=\left\{\left[\ell \mathrm{C} \theta_{\mathrm{w}}-r \mathrm{C}\left(\theta_{\mathrm{d}}+\alpha\right)\right]^{2}+\left[\ell \mathrm{S} \theta_{\mathrm{w}}+r \mathrm{~S}\left(\theta_{\mathrm{d}}+\alpha\right)\right]^{2}\right\}^{1 / 2}
$$

\subsection{Degree of wear}

A second structural performance index may be defined qualitatively as the overall degree of wear (DOW) between the crank pin and the wheel slot during a motion cycle. Assume that the friction between the two elements is Coulomb friction and each slot is under equal lubrication and abrasion conditions. Also assume that variations of the contact area between the roller and the slot profile are small and negligible. This degree of wear is proportional in magnitude to the product of the normal contact (compressive) force and the sliding velocity of the pin in the slot. Thus, the degree of wear for a cycle of motion is given as

$$
\mathrm{DOW}=k \int_{0}^{t}\left|\boldsymbol{f}_{\mathrm{c}} \cdot \boldsymbol{v}\right| \mathrm{d} t
$$

where $f_{\mathrm{c}}$ is the compressive contact force given by equation (13), $\boldsymbol{v}$ is the sliding velocity given by $\left({ }^{\mathrm{f}} \boldsymbol{v}_{\mathrm{p} 2}-{ }^{\mathrm{f}} \boldsymbol{v}_{\mathrm{p} 1}\right)$ and $k$ is a constant coefficient. This index can provide a certain insight into the dynamic property of the mechanism.

\section{EFFECTS OF VARIATION IN DESIGN PARAMETERS ON THE MECHANISM PERFORMANCE}

In this section, the effects of variations in various geometry parameters, the roller radius $r$, base wheel radius $\ell$, offset angle $\theta_{\text {off }}$ and initial crank angle $\theta_{\mathrm{do}}$, on the values of maximum stress and degree of wear are investigated. The results provide not only an overall look on the nature of the mechanism but also an indepth understanding prior to the design optimization problem in the following section. Here, it is assumed that a four-slot wheel $(N=4)$ is to be designed. As for the motion curve, many different choices are possible. In this work, for the sake of simplicity and clarity, the 


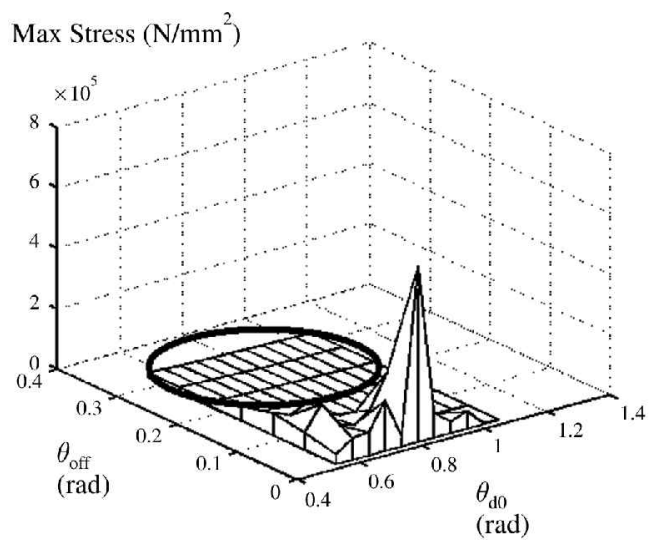

(a)

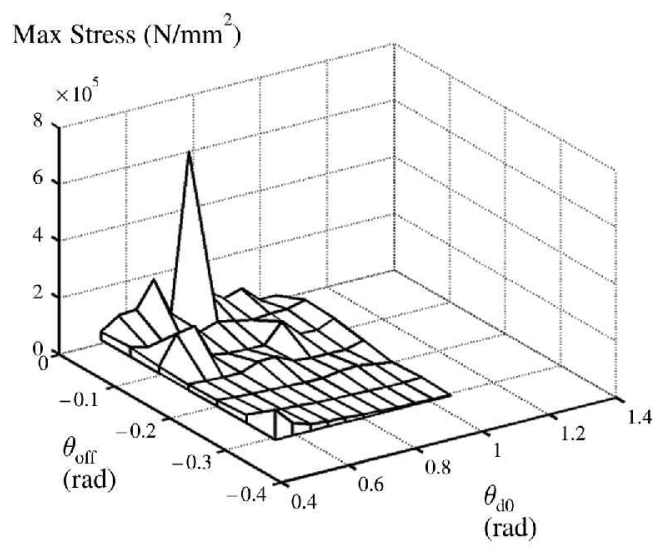

(c)

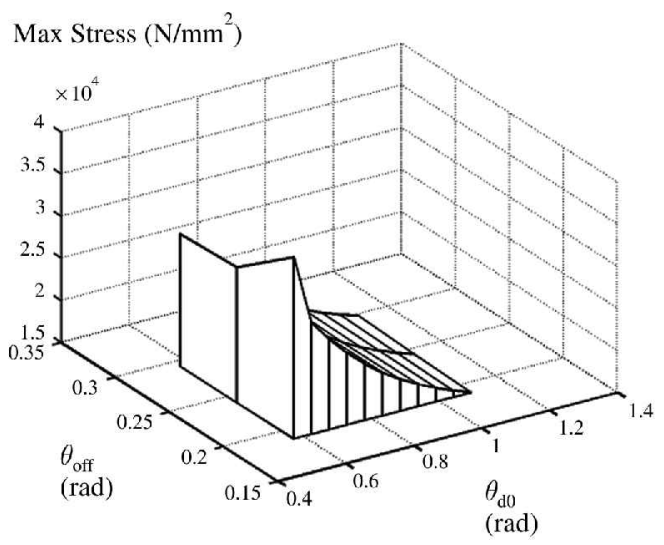

(b)

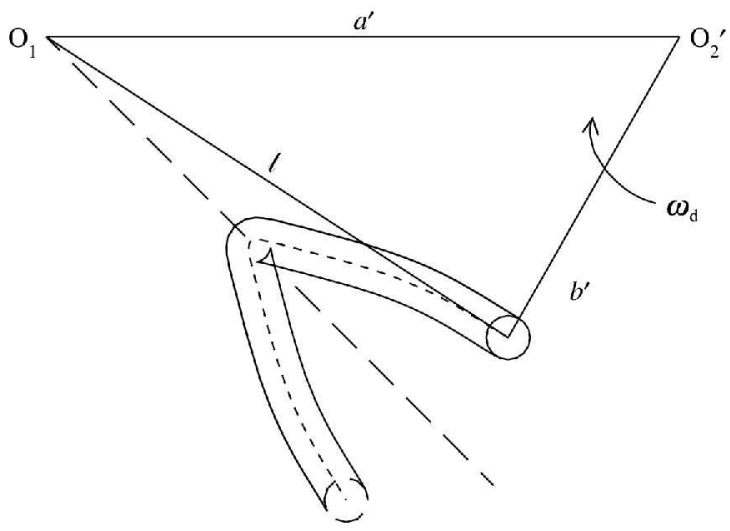

(d)

Fig. 3 (a) Plot of maximum stress $\sigma_{\mathrm{m}}\left(\ell=100, r=4,0 \leqslant \theta_{\text {off }} \leqslant 18^{\circ}, 30^{\circ} \leqslant \theta_{\mathrm{d} 0} \leqslant 60^{\circ}\right)$. (b) Magnification of Fig. 3a $\left(10^{\circ} \leqslant \theta_{\text {off }} \leqslant 18^{\circ}\right)$. (c) Plot of maximum stress $\sigma_{\mathrm{m}}\left(\ell=100, r=4,-18^{\circ} \leqslant \theta_{\text {off }} \leqslant 0\right.$, $\left.30^{\circ} \leqslant \theta_{\mathrm{d} 0} \leqslant 60^{\circ}\right)$. (d) Slot profile showing intersection and undercutting $\left(r=4, \theta_{\text {off }}=-12^{\circ}, \theta_{\mathrm{d} 0}=\right.$ $\left.60^{\circ}\right)$

simplest class of polynomial functions, the 3-4-5 polynomial, is adopted as the displacement curve for the wheel. Note that the 3-4-5 polynomial is continuous up to the acceleration curve and has zero acceleration values at the beginning and final stages. The numerical data for material properties are chosen as $E_{1}=E_{2}=200 \mathrm{GPa}, \quad v_{1}=v_{2}=0.3, \quad I_{\mathrm{w}}=12410 \mathrm{~kg} \mathrm{~mm}^{2}$, $h=10 \mathrm{~mm}$ and $\omega_{\mathrm{d}}=1 \mathrm{rad} / \mathrm{s}$. Figures 3 to 6 show the influence of the geometry parameters $\left(r, \theta_{\text {off }}, \theta_{\mathrm{do}}\right)$ on the maximum stress $\sigma_{\mathrm{m}}\left(\mathrm{N} / \mathrm{mm}^{2}\right)$ for a constant base wheel radius $\ell=100 \mathrm{~mm}$. In Fig. 3a, values of the parameter are given as $r=4 \mathrm{~mm}, 0 \leqslant \theta_{\text {off }} \leqslant 18^{\circ}, 30^{\circ} \leqslant \theta_{\mathrm{do}} \leqslant 60^{\circ}$. As can be seen from the figure, a few spikes exist in the plot when $\theta_{\text {off }}$ and $\theta_{\mathrm{do}}$ are relatively small. These spikes usually occur at the places where the curvature of the slot is large or the slot has intersection/undercutting. When the offset value $\theta_{\text {off }}$ becomes larger, the value of $\sigma_{\mathrm{m}}$ becomes smaller, as magnified in Fig. $3 \mathrm{~b}$. On the other hand, Fig. 3c shows the result of $\sigma_{\mathrm{m}}$ under the same condition as in Fig. 3a except that $\theta_{\text {off }}$ is given from 0 to $-18^{\circ}$. The overall distribution of $\sigma_{\mathrm{m}}$ is similar to that of Fig. 3a. When the magnitude of $\theta_{\text {off }}$ and $\theta_{\text {do }}$

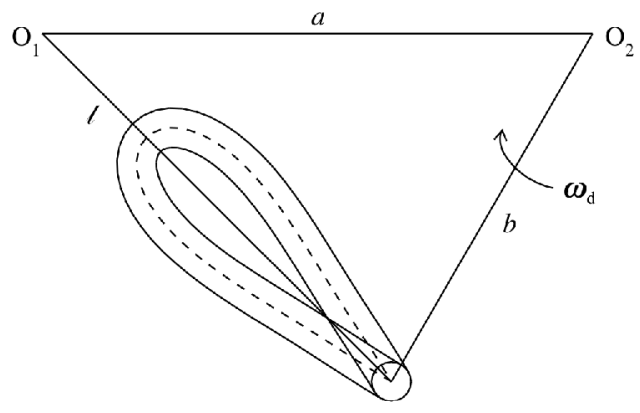

Fig. 4 Intersection of the profile without undercutting, yet resulting in engineering impracticality $(N=4$, $\left.\theta_{\mathrm{d}}=60^{\circ}, \theta_{\text {off }}=0^{\circ}, \ell=100, r=4\right)$ 


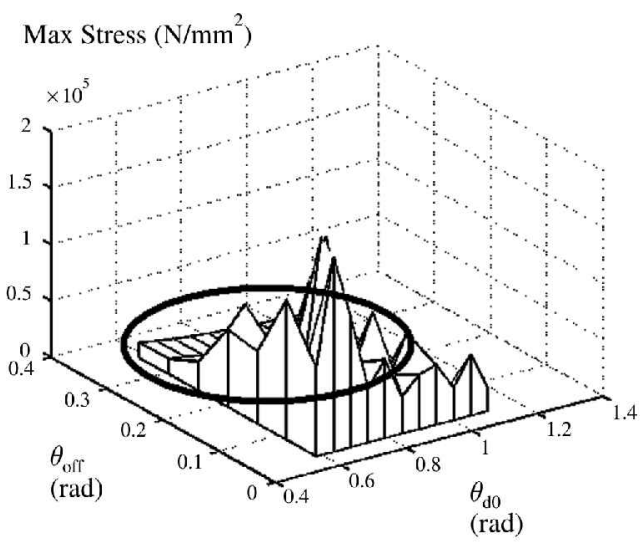

(a)

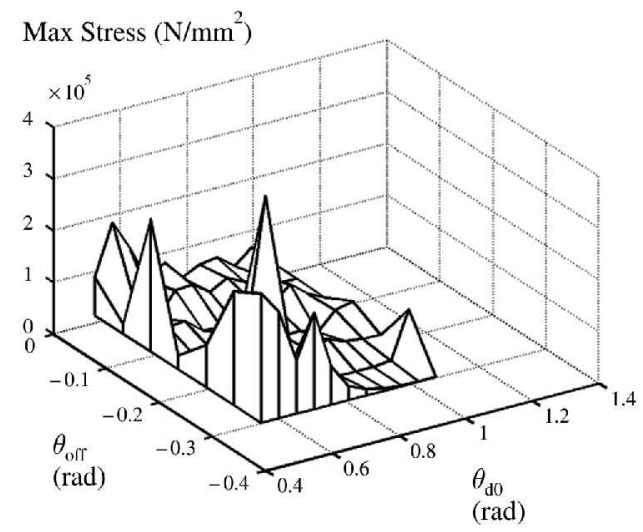

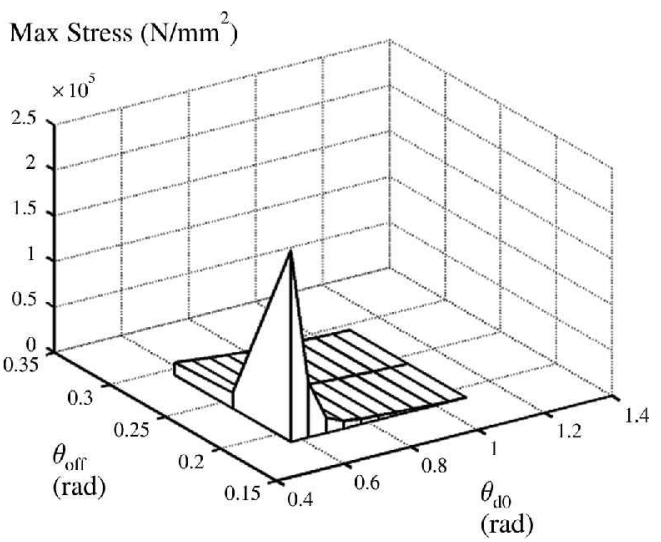

(b)

(c)

Fig. 5 (a) Plot of maximum stress $\sigma_{\mathrm{m}}\left(\ell=100, r=6,0 \leqslant \theta_{\text {off }} \leqslant 18^{\circ}, 30^{\circ} \leqslant \theta_{\mathrm{d} 0} \leqslant 60^{\circ}\right.$. (b) Magnification of Fig. 5a $\left(10^{\circ} \leqslant \theta_{\text {off }} \leqslant 18^{\circ}\right)$. (c) Plot of maximum stress $\sigma_{\mathrm{m}}\left(\ell=100, r=6,-18^{\circ} \leqslant \theta_{\text {off }} \leqslant 0\right.$, $\left.30^{\circ} \leqslant \theta_{\mathrm{d} 0} \leqslant 60^{\circ}\right)$

become larger, $\sigma_{\mathrm{m}}$ tends to be smaller. A typical undercutting (and intersection) of the slot can also be found in the design shown by Fig. 3d, where $\theta_{\text {off }}=-12^{\circ}, \theta_{\mathrm{do}}=60^{\circ}$. Another type of intersection of the slot that cannot be detected by the undercutting criteria of equations (10a) and (10b) occurs when the offset value $\theta_{\text {off }}$ is zero or at its vicinity as shown in Fig. 4. In Fig. 4, the beginning portion of the convex (inner) curve intersects with the ending portion, resulting in engineering impracticality. Therefore, such designs should also be avoided. Figures 5 to 7 show the results as the roller radius is increasing. Similar conditions occur in these cases, i.e. as the offset value and initial crank angle become relatively large and the distribution of $\sigma_{\mathrm{m}}$ becomes smooth. In summary, the effect of the variation of the design and geometric parameter on the maximum stress can be concluded from the above analysis as: the maximum stress $\sigma_{\mathrm{m}}$ will decrease as the magnitude of the offset value, $\theta_{\text {off }}$, increases, the initial crank angle, $\theta_{\mathrm{do}}$, increases and the roller radius increases. The variations of the values of the DOW with respect to the design parameters $\left(\theta_{\text {off }}\right.$, $\left.\theta_{\mathrm{do}}, r\right)$ are shown in Figs 8 a to d. A general trend from the effect can also be concluded as follows. The value of the DOW decreases as the initial crank angle, $\theta_{\mathrm{do}}$, increases and the roller radius decreases. Also, the value of the DOW tends to decrease as the offset value $\theta_{\text {off }}$ goes into negative value. Note that intersections or looping can also appear in the design, as indicated by the area shown in Fig. 8a. 


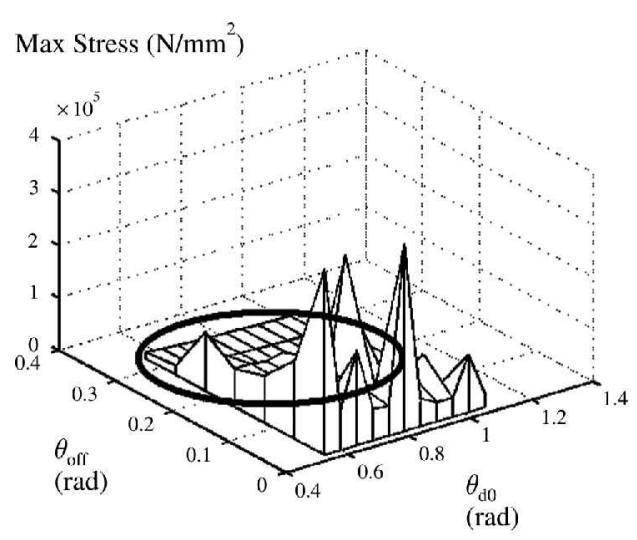

(a)

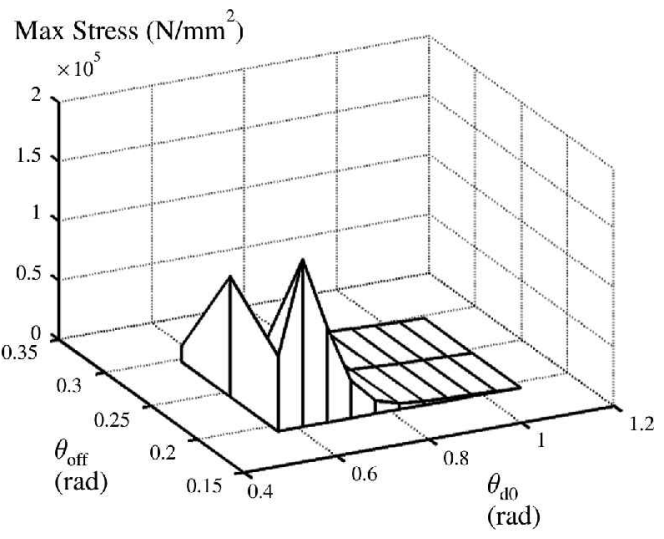

(b)

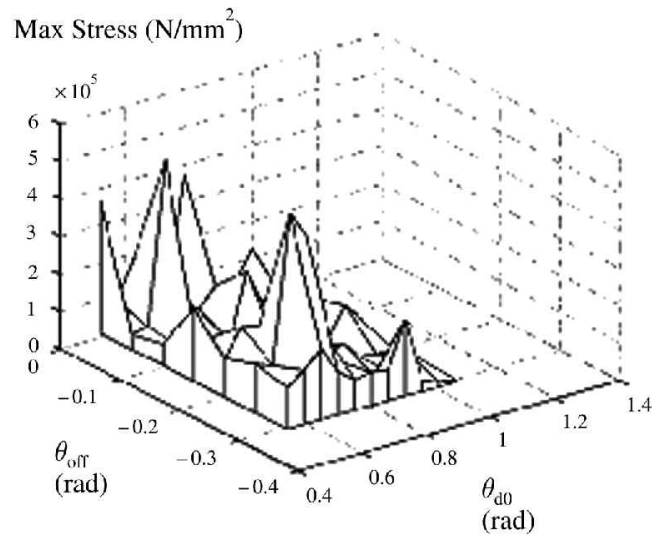

(c)

Fig. 6 (a) Plot of maximum stress $\sigma_{\mathrm{m}}\left(\ell=100, r=8,0 \leqslant \theta_{\text {off }} \leqslant 18^{\circ}, 30^{\circ} \leqslant \theta_{\mathrm{d} 0} \leqslant 60^{\circ}\right)$. (b) Magnification of Fig. $6 \mathrm{a}\left(10^{\circ} \leqslant \theta_{\text {off }} \leqslant 18^{\circ}\right)$. (c) Plot of maximum stress $\sigma_{\mathrm{m}}\left(\ell=100, \quad r=8,-18^{\circ} \leqslant \theta_{\text {off }} \leqslant 0\right.$, $\left.30^{\circ} \leqslant \theta_{\mathrm{d} 0} \leqslant 60^{\circ}\right)$

\subsection{Design optimization}

From the above results, to avoid the intersection and undercutting of the profile, ranges of the parameters should be properly chosen for the design of the mechanism. After the ranges of parameters that yield no intersection for the slot profile have been determined, the design procedure can be further formulated as a design optimization problem. For example, by selecting the DOW as the objective function, the design optimization problem can be written as

$$
\begin{array}{ll}
\text { Minimize } & \int_{0}^{t}\left|\boldsymbol{f}_{\mathrm{c}} \cdot \boldsymbol{v}\right| \mathrm{d} t \\
\text { Subject to } & \left|\rho_{\text {min }}\right|>r \\
& \left|\rho_{\text {fmin }}\right|>r \\
& -18^{\circ} \leqslant \theta_{\text {off }} \leqslant 0^{\circ} \\
& 4 \leqslant r \leqslant 10 \\
& 30^{\circ} \leqslant \theta_{\mathrm{d} 0} \leqslant 60^{\circ}
\end{array}
$$

The sequential quadric programming (SQP) method is used as the solution technique for the single objective optimization problem. Figure 9 shows the results of the optimization and the corresponding geometry. Similarly, a set of optimum design variables can also be obtained by choosing the maximum stress as the objective function:

$$
\begin{array}{ll}
\text { Minimize } & \sigma_{\mathrm{m}} \\
\text { Subject to } & \left|\rho_{\text {min }}\right|>r \\
& \left|\rho_{\text {fmin }}\right|>r \\
& 0 \leqslant \theta_{\text {off }} \leqslant 7.2^{\circ} \\
& 4 \leqslant r \leqslant 10 \\
& 30^{\circ} \leqslant \theta_{\mathrm{d} 0} \leqslant 55^{\circ}
\end{array}
$$

Figure 10 shows the result of the optimization. 


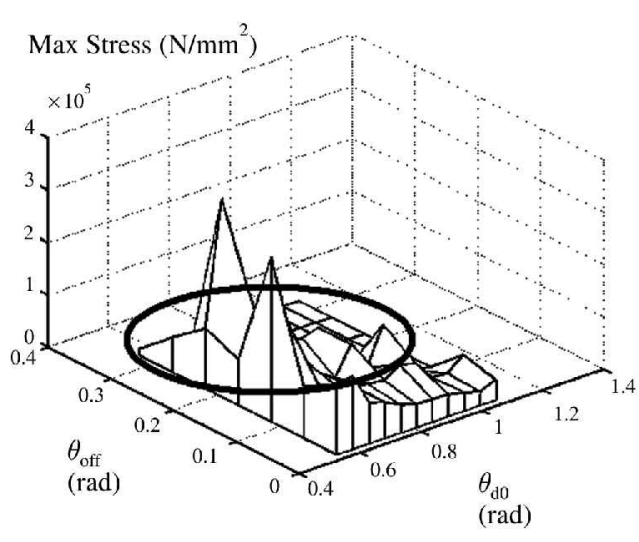

(a)

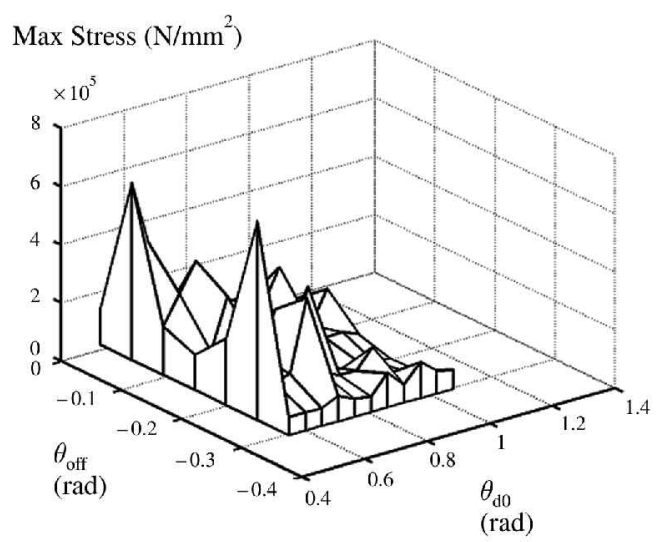

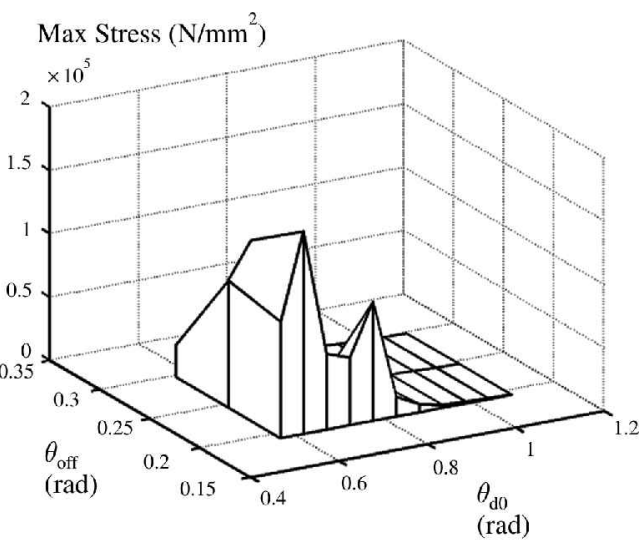

(b)

(c)

Fig. 7 (a) Plot of maximum stress $\sigma_{\mathrm{m}}\left(\ell=100, r=10,0 \leqslant \theta_{\text {off }} \leqslant 18^{\circ}, 30^{\circ} \leqslant \theta_{\mathrm{d} 0} \leqslant 60^{\circ}\right)$. (b) Magnification of Fig. $7 \mathrm{a}\left(10^{\circ} \leqslant \theta_{\text {off }} \leqslant 18^{\circ}\right)$. (c) Plot of maximum stress $\sigma_{\mathrm{m}}\left(\ell=100, r=10,-18^{\circ} \leqslant \theta_{\text {off }} \leqslant 0\right.$, $\left.30^{\circ} \leqslant \theta_{\mathrm{d} 0} \leqslant 60^{\circ}\right)$

\section{CONCLUSION}

Based on the theory of conjugate surfaces, the mathematical expressions for the surface geometry of the Geneva mechanism with curved slots are derived. The influence of variations in various geometry parameters on the structural performance of the mechanism is also investigated. The analyses lead to an optimal design of the Geneva mechanism as well as optimum values for the design parameters. It is hoped that the method demonstrated in this work can provide a useful means of obtaining a better design of the Geneva mechanism with curved slots. 


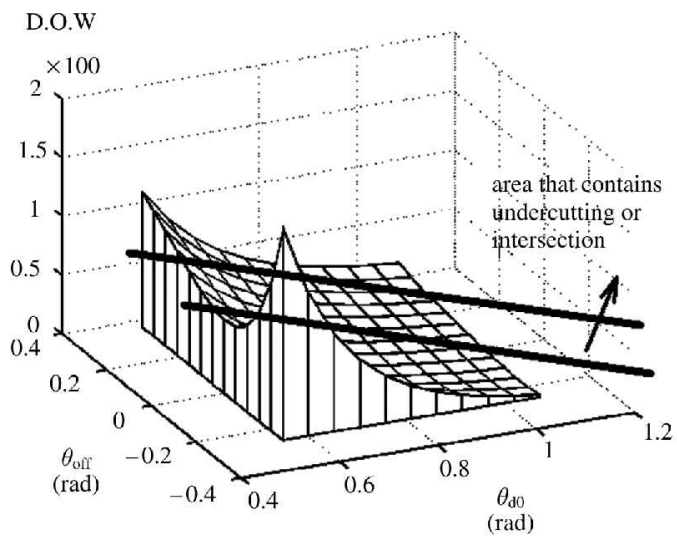

(a)

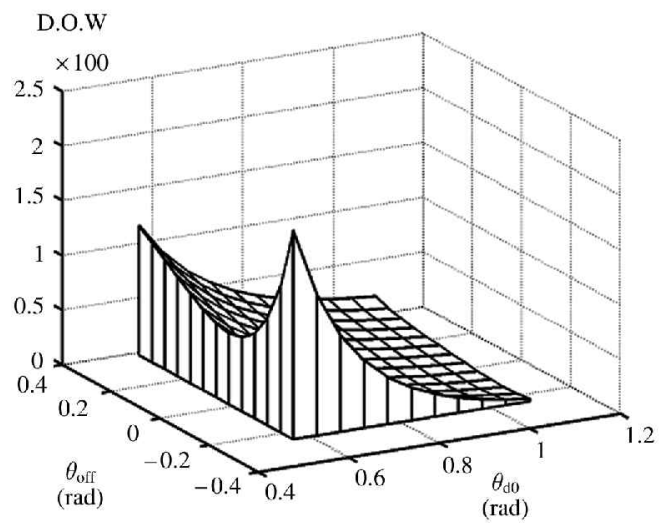

(c)

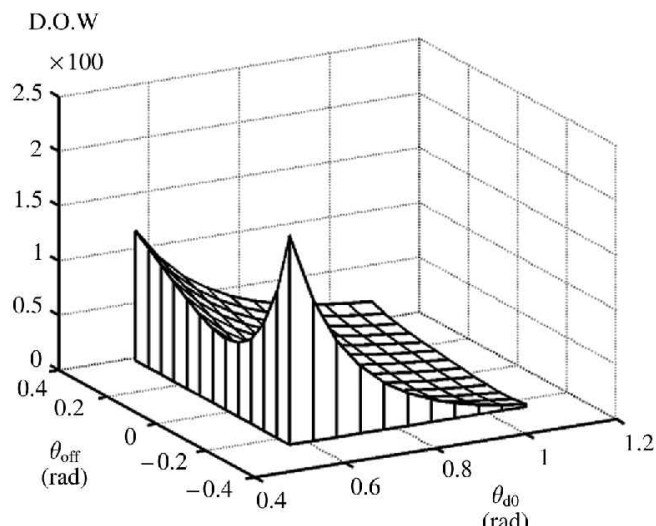

(b)

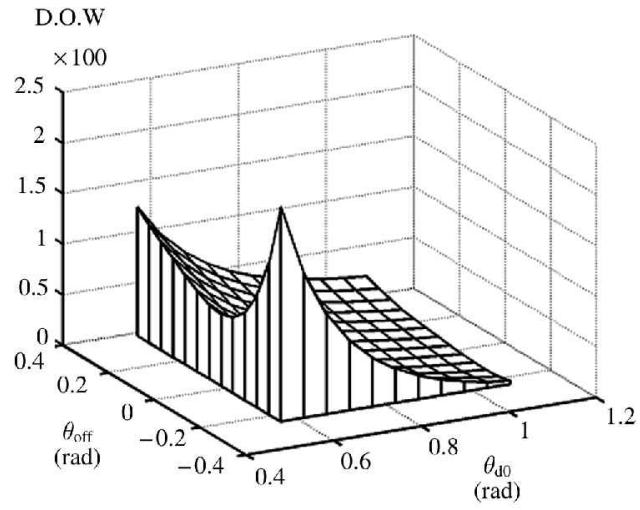

(d)

Fig. 8 (a) Plot of DOW $\left(\ell=100, r=4,-18^{\circ} \leqslant \theta_{\text {off }} \leqslant 18^{\circ}, 30^{\circ} \leqslant \theta_{\mathrm{d} 0} \leqslant 60^{\circ}\right)$. (b) Plot of DOW $(\ell=100$, $\left.r=6,-18^{\circ} \leqslant \theta_{\text {off }} \leqslant 18^{\circ}, 30^{\circ} \leqslant \theta_{\mathrm{d} 0} \leqslant 60^{\circ}\right)$. (c) Plot of DOW $\left(\ell=100, r=8,-18^{\circ} \leqslant \theta_{\text {off }} \leqslant 18^{\circ}\right.$, $30^{\circ} \leqslant \theta_{\mathrm{d} 0} \leqslant 60^{\circ}$ ). (d) Plot of DOW

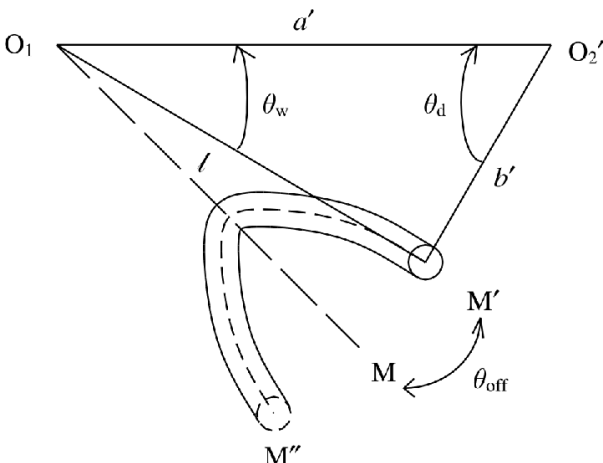

Fig. 9 Optimized design for minimal degree of wear $\left(\theta_{\mathrm{d} 0}=60^{\circ}, \theta_{\text {off }}=-14.5^{\circ}, r=4\right)$

\section{ACKNOWLEDGEMENT}

The authors wish to thank Professor Ching-Huan Tseng of National Chiao Tung University for his kind offer of the MOST (Multifunctional Optimization System Tool) package for optimizing the calculations.

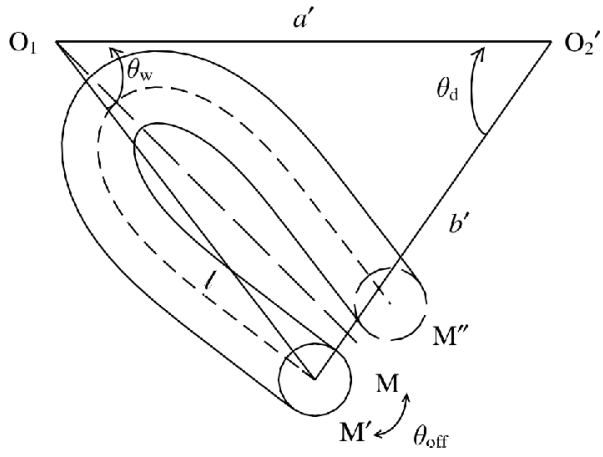

Fig. 10 Optimized design for minimal maximum stress $\left(\theta_{\mathrm{d} 0}=55^{\circ}, \theta_{\mathrm{off}}=7.2^{\circ}, r=8.5\right)$

\section{REFERENCES}

1 Dijksman, E. A. Jerk-free Geneva wheel driving. J. Mechanisms, 1966, 1, 235-283.

2 Bagci, C. Synthesis of double-crank driven mechanisms with adjustable motion and dwell time ratios. Mech. Mach. Theory, 1977, 12(6), 619-638. 
3 Yang, A. T. and Hsia, L. M. Multistage geared Geneva mechanism. Trans. ASME, J. Mech. Des., 1979, 101, 4146.

4 Fenton, R. G. Geneva mechanisms connected in series. Trans. ASM E, J. Engng for Industry, 1975, 97, 603-608.

5 Al-Sabeeh, A. K. Double crank external Geneva mechanism. Trans. ASME, J. Mech. Des., 1993, 115, 666-670.

6 Sadek, K. S. H., Lloyd, J. L. and Smith, M. R. A new design of Geneva drive to reduce shock loading. Mech. Mach. Theory, 1990, 25, 589-595.

7 Cheng, C. Y. and Lin, Y. Improving dynamic performance of the Geneva mechanism using non-linear spring elements. Mech. Mach. Theory, 1995, 30, 119-129.
8 Fenton, R. G., Zhang, Y. and Xu, J. Development of a new Geneva mechanism with improved kinematic characteristics. Trans. ASME, J. Mech. Des., 1991, 113, 40-45.

9 Lee, H. P. Design of a Geneva mechanism with curved slots using parametric polynomials. Mech. Mach. Theory, 1998, 33(3), 321-329.

10 Chakraborty, J. and Dhande, S. G. Kinematics and Geometry of Planar and Spatial Cam Mechanisms, 1977 (John Wiley, New York).

11 Litvin, F. L. Theory of Gearing, 1989 (NASA, Washington, DC).

12 Norton, R. L. Design of Machinery, 2nd edition, 1999 (WCB/McGraw-Hill, New York).

\section{APPENDIX}

For the case of a roller driver, the equation for the radius of curvature of the slot profile can be written as

$$
\rho=\frac{\left[\left(\mathrm{d} x / \mathrm{d} \theta_{\mathrm{d}}\right)^{2}+\left(\mathrm{d} y / \mathrm{d} \theta_{\mathrm{d}}\right)^{2}\right]^{3 / 2}}{\left(\mathrm{~d} x / \mathrm{d} \theta_{\mathrm{d}}\right)\left(\mathrm{d}^{2} y / \mathrm{d} \theta_{\mathrm{d}}^{2}\right)-\left(\mathrm{d} y / \mathrm{d} \theta_{\mathrm{d}}\right)\left(\mathrm{d}^{2} x / \mathrm{d} \theta_{\mathrm{d}}^{2}\right)}
$$

where

$$
\begin{aligned}
& x=a \mathbf{C} \theta_{\mathrm{w}}-b \mathrm{C}\left(\theta_{\mathrm{w}}+\theta_{\mathrm{d}}\right)-r \mathrm{C}\left(\theta_{\mathrm{w}}+\theta_{\mathrm{d}}+\alpha\right) \\
& \left.y=a \mathrm{~S} \theta_{\mathrm{w}}-b \mathrm{~S}\left(\theta_{\mathrm{w}}+\theta_{\mathrm{d}}\right)-r \mathrm{~S}\left(\theta_{\mathrm{w}}+\theta_{\mathrm{d}}\right)+\alpha\right) \\
& \frac{\mathrm{d} x}{\mathrm{~d} \theta_{\mathrm{w}}}=\frac{\mathrm{d} x}{\mathrm{~d} \theta_{\mathrm{d}}}\left(\frac{1}{\theta_{\mathrm{w}}^{\prime}}\right) \\
& =\left[-a \theta_{\mathrm{w}}^{\prime} \mathrm{S} \theta_{\mathrm{w}}-b\left(1+\theta_{\mathrm{w}}^{\prime}\right) \mathrm{S}\left(\theta_{\mathrm{w}}+\theta_{\mathrm{d}}\right)+r\left(1+\theta_{\mathrm{w}}^{\prime}+\alpha^{\prime}\right) \mathrm{S}\left(\theta_{\mathrm{w}}+\theta_{\mathrm{d}}+\alpha\right)\right]\left(\frac{1}{\theta_{\mathrm{w}}^{\prime}}\right) \\
& \frac{\mathrm{d} y}{\mathrm{~d} \theta_{\mathrm{w}}}=\frac{\mathrm{d} y}{\mathrm{~d} \theta_{\mathrm{d}}}\left(\frac{1}{\theta_{\mathrm{w}}^{\prime}}\right) \\
& =\left[a \theta_{\mathrm{w}}^{\prime} \mathrm{C} \theta_{\mathrm{w}}-b\left(1+\theta_{\mathrm{w}}^{\prime}\right) \mathrm{C}\left(\theta_{\mathrm{w}}+\theta_{\mathrm{d}}\right)-r\left(1+\theta_{\mathrm{w}}^{\prime}+\alpha^{\prime}\right) \mathrm{C}\left(\theta_{\mathrm{w}}+\theta_{\mathrm{d}}+\alpha\right)\right]\left(\frac{1}{\theta_{\mathrm{w}}^{\prime}}\right) \\
& \frac{\mathrm{d}^{2} x}{\mathrm{~d} \theta_{\mathrm{w}}^{2}}=\frac{\mathrm{d}^{2} x}{\mathrm{~d} \theta_{\mathrm{d}}^{2}}\left(\frac{1}{\theta_{\mathrm{w}}^{\prime}}\right)^{2}+\frac{\mathrm{d} x}{\mathrm{~d} \theta_{\mathrm{d}}}\left[\frac{-\theta_{\mathrm{w}}^{\prime \prime}}{\left(\theta_{\mathrm{w}}^{\prime}\right)^{3}}\right] \\
& =\left[-a \theta_{\mathrm{w}}^{\prime \prime} \mathrm{S} \theta_{\mathrm{w}}-a \theta_{\mathrm{w}}^{\prime 2} \mathrm{C} \theta_{\mathrm{w}}+b \theta_{\mathrm{w}}^{\prime \prime} \mathrm{S}\left(\theta_{\mathrm{w}}+\theta_{\mathrm{d}}\right)+b\left(1+\theta_{\mathrm{w}}^{\prime}\right)^{2} \mathrm{C}\left(\theta_{\mathrm{w}}+\theta_{\mathrm{d}}\right)+r\left(\theta_{\mathrm{w}}^{\prime \prime}+\alpha^{\prime \prime}\right) \mathrm{S}\left(\theta_{\mathrm{w}}+\theta_{\mathrm{d}}+\alpha\right)\right. \\
& \left.+r\left(1+\theta_{\mathrm{w}}^{\prime}+\alpha^{\prime}\right)^{2} \mathrm{C}\left(\theta_{\mathrm{w}}+\theta_{\mathrm{d}}+\alpha\right)\right]\left(\frac{1}{\theta_{\mathrm{w}}^{\prime}}\right)^{2} \\
& +\left[-a \theta_{\mathrm{w}}^{\prime} \mathrm{S} \theta_{\mathrm{w}}-b\left(1+\theta_{\mathrm{w}}^{\prime}\right) \mathrm{S}\left(\theta_{\mathrm{w}}+\theta_{\mathrm{d}}\right)+r\left(1+\theta_{\mathrm{w}}^{\prime}+\alpha^{\prime}\right) \mathrm{S}\left(\theta_{\mathrm{w}}+\theta_{\mathrm{d}}+\alpha\right)\right]\left[\frac{-\theta_{\mathrm{w}}^{\prime \prime}}{\left(\theta_{\mathrm{w}}^{\prime}\right)^{3}}\right] \\
& \frac{\mathrm{d}^{2} y}{\mathrm{~d} \theta_{\mathrm{w}}^{2}}=\frac{\mathrm{d}^{2} y}{\mathrm{~d} \theta_{\mathrm{d}}^{2}}\left(\frac{1}{\theta_{\mathrm{w}}^{\prime}}\right)^{2}+\frac{\mathrm{d} y}{\mathrm{~d} \theta_{\mathrm{d}}}\left[\frac{-\theta_{\mathrm{w}}^{\prime \prime}}{\left(\theta_{\mathrm{w}}^{\prime}\right)^{3}}\right] \\
& =\left[a \theta_{\mathrm{w}}^{\prime \prime} \mathrm{C} \theta_{\mathrm{w}}-a \theta_{\mathrm{w}}^{\prime 2} \mathrm{~S} \theta_{\mathrm{w}}-b \theta_{\mathrm{w}}^{\prime \prime} \mathrm{C}\left(\theta_{\mathrm{w}}+\theta_{\mathrm{d}}\right)+b\left(1+\theta_{\mathrm{w}}^{\prime}\right)^{2} \mathrm{~S}\left(\theta_{\mathrm{w}}+\theta_{\mathrm{d}}\right)-r\left(\theta_{\mathrm{w}}^{\prime \prime}+\alpha^{\prime \prime}\right) \mathrm{C}\left(\theta_{\mathrm{w}}+\theta_{\mathrm{d}}+\alpha\right)\right. \\
& \left.+r\left(1+\theta_{\mathrm{w}}^{\prime}+\alpha^{\prime}\right)^{2} \mathrm{~S}\left(\theta_{\mathrm{w}}+\theta_{\mathrm{d}}+\alpha\right)\right]\left(\frac{1}{\theta_{\mathrm{w}}^{\prime}}\right)^{2} \\
& +\left[a \theta_{\mathrm{w}}^{\prime} \mathrm{C} \theta_{\mathrm{w}}-b\left(1+\theta_{\mathrm{w}}^{\prime}\right) \mathrm{C}\left(\theta_{\mathrm{w}}+\theta_{\mathrm{d}}\right)-r\left(1+\theta_{\mathrm{w}}^{\prime}+\alpha^{\prime}\right) \mathrm{C}\left(\theta_{\mathrm{w}}+\theta_{\mathrm{d}}+\alpha\right)\right]\left[\frac{-\theta_{\mathrm{w}}^{\prime \prime}}{\left(\theta_{\mathrm{w}}^{\prime}\right)^{3}}\right]
\end{aligned}
$$




$$
\begin{aligned}
\alpha= & \tan ^{-1}\left[\frac{a \theta_{\mathrm{w}}^{\prime} \mathrm{S} \theta_{\mathrm{d}}}{\left(1+\theta_{\mathrm{w}}^{\prime}\right) b-a \theta_{\mathrm{w}}^{\prime} \mathrm{C} \theta_{\mathrm{d}}}\right] \\
\alpha^{\prime}= & \frac{\mathrm{d} \alpha}{\mathrm{d} \theta_{\mathrm{d}}}=\frac{-a \theta_{\mathrm{w}}^{\prime} \mathrm{C}\left(\theta_{\mathrm{d}}+\alpha\right)-a \theta_{\mathrm{w}}^{\prime \prime} \mathrm{S}\left(\theta_{\mathrm{d}}+\alpha\right)+b \theta_{\mathrm{w}}^{\prime \prime} \mathrm{S} \alpha}{b\left(1+\theta_{\mathrm{w}}^{\prime}\right) \mathrm{C} \alpha-a \theta_{\mathrm{w}}^{\prime} \mathrm{C}\left(\theta_{\mathrm{d}}+\alpha\right)} \\
\alpha^{\prime \prime}= & \frac{\mathrm{d}^{2} \alpha}{\mathrm{d} \theta_{\mathrm{d}}^{2}} \\
= & {\left[-a \theta_{\mathrm{w}}^{\prime \prime} \mathrm{C}\left(\theta_{\mathrm{d}}+\alpha\right)+a \theta_{\mathrm{w}}^{\prime}\left(1+\alpha^{\prime}\right) \mathrm{S}\left(\theta_{\mathrm{d}}+\alpha\right)-a \theta_{\mathrm{w}}^{\prime \prime \prime} \mathrm{S}\left(\theta_{\mathrm{d}}+\alpha\right)-a \theta_{\mathrm{w}}^{\prime \prime}\left(1+\alpha^{\prime}\right) \mathrm{C}\left(\theta_{\mathrm{d}}+\alpha\right)+b \theta_{\mathrm{w}}^{\prime \prime \prime} \mathrm{S} \alpha+b \theta_{\mathrm{w}}^{\prime \prime} \alpha^{\prime} \mathrm{C} \alpha\right] } \\
& \times\left[\left(1+\theta_{\mathrm{w}}^{\prime}\right) b \mathrm{C} \alpha-a \theta_{\mathrm{w}}^{\prime} \mathrm{C}\left(\theta_{\mathrm{d}}+\alpha\right)\right]-\left[-a \theta_{\mathrm{w}}^{\prime} \mathrm{C}\left(\theta_{\mathrm{d}}+\alpha\right)-a \theta_{\mathrm{w}}^{\prime \prime} \mathrm{S}\left(\theta_{\mathrm{d}}+\alpha\right)+b \theta_{\mathrm{w}}^{\prime \prime} \mathrm{S} \alpha\right] \\
& \times \frac{b \theta_{\mathrm{w}}^{\prime \prime} \mathrm{C} \alpha-b\left(1+\theta_{\mathrm{w}}^{\prime}\right) \alpha^{\prime} \mathrm{S} \alpha-a \theta_{\mathrm{w}}^{\prime \prime} \mathrm{C}\left(\theta_{\mathrm{d}}+\alpha\right)+a \theta_{\mathrm{w}}^{\prime}\left(1+\alpha^{\prime}\right) \mathrm{S}\left(\theta_{\mathrm{d}}+\alpha\right)}{\left[b\left(1+\theta_{\mathrm{w}}^{\prime}\right) \mathrm{C} \alpha-a \theta_{\mathrm{w}}^{\prime} \mathrm{C}\left(\theta_{\mathrm{d}}+\alpha\right)\right]^{2}}
\end{aligned}
$$

